\title{
Serum inflammatory markers and colorectal cancer risk and survival
}

\begin{abstract}
Sundeep Ghuman ${ }^{1}$, Mieke Van Hemelrijck ${ }^{1}$, Hans Garmo ${ }^{1,2}$, Lars Holmberg ${ }^{1,2,3}$, Håkan Malmström ${ }^{4}$, Mats Lambe ${ }^{2,5}$, Niklas Hammar ${ }^{6,7}$, Göran Walldius ${ }^{7}$, Ingmar Jungner ${ }^{8}$ and Wahyu Wulaningsih*,1,9

${ }^{1}$ Cancer Epidemiology Group, Division of Cancer Studies, King's College London, London, UK; ${ }^{2}$ Regional Cancer Centre, Uppsala, Sweden; ${ }^{3}$ Department of Surgical Sciences, Uppsala University Hospital, Uppsala, Sweden; ${ }^{4}$ Department of Epidemiology, Institute of Environmental Medicine, Karolinska Institutet, Stockholm, Sweden; ${ }^{5}$ Department of Medical Epidemiology and Biostatistics, Karolinska Institutet, Stockholm, Sweden; ${ }^{6}$ AstraZeneca R\&D, Mölndal, Sweden; ${ }^{7}$ Department of Cardiovascular Epidemiology, Institute of Environmental Medicine, Karolinska Institutet, Stockholm, Sweden; ${ }^{8}$ Department of Medicine, Clinical Epidemiological Unit, Karolinska Institutet and CALAB Research, Stockholm, Sweden and ${ }^{9}$ Medical Research Council Unit for Lifelong Health and Ageing at University College London, London, UK
\end{abstract}

Background: Inflammation has been linked with development of some cancers. We investigated systemic inflammation in relation to colorectal cancer incidence and subsequent survival using common serum inflammatory markers

Design: A cohort of men and women aged 20 years and older in greater Stockholm area with serum C-reactive protein (CRP) and albumin measured between 1986 and 1999 were included $(n=325599)$. A subset of these had baseline measurements of haptoglobin and leukocytes. Multivariable Cox regression was performed to assess risk of colorectal cancer by levels of inflammatory markers, adjusting for potential confounders. Analyses were stratified by circulating glucose, total cholesterol and triglycerides. Overall and CRC-specific death following diagnosis were assessed as secondary outcomes.

Results: A total of 4764 individuals were diagnosed with colorectal cancer. A positive association between haptoglobin and colorectal cancer incidence was found (hazard ratio (HR): 1.17; 95\% Cl: 1.06-1.28). A positive association was also observed with leukocytes (HR: 1.21; 95\% Cl: 1.03-1.42). No evidence of association was noted between CRP and colorectal cancer risk. Higher risks of all-cause death were seen with haptoglobin and leukocytes levels. Higher haptoglobin levels were linked with an increased risk of colorectal cancer death (HR: 1.19; 95\% Cl: 1.01-1.41).

Conclusions: Prediagnostic systemic inflammation may impact colorectal cancer incidence and survival; therefore, prompting investigations linking inflammatory pathways preceding colorectal cancer with disease severity and progression.

Evidence suggesting a role for inflammation in colorectal carcinogenesis is growing (Hanahan and Weinberg, 2011). For instance, inflammatory bowel disease, reflecting local inflammation of the colon, has been associated with an increased risk of colorectal cancer (Jess et al, 2012). The role of systemic inflammation in colon carcinogenesis, however, remains unclear. Chronic inflammation may initiate and promote cancer through the generation of proinflammatory cytokines and reactive oxygen species, such as interleukin-6 (IL-6), which activates transcription factors that can promote the growth of a tumour (Meira et al, 2008). Increases in white blood cells can also lead to a 'respiratory burst' due to an increased uptake of oxygen, resulting in more reactive oxygen species at the site of damage and DNA damage consequently (Reuter et al, 2010).

In the context of colorectal cancer, over 19 observational studies have investigated a link with prediagnostic levels of inflammatory markers over the past decade (Supplementary Table S1). Most of these studies have used C-reactive protein (CRP). Findings varied,

${ }^{\star}$ Correspondence: Dr W Wulaningsih; E-mail: wahyu.wulaningsih@kcl.ac.uk

Received 18 November 2016; revised 31 January 2017; accepted 17 March 2017; published online 4 April 2017

(C) 2017 Cancer Research UK. All rights reserved 0007-0920/17 
with nine studies having reported a positive association between CRP and colorectal cancer risk. A meta-analysis in 2013 found no statistical significance (hazard ratio (HR) 1.055; 95 CI: $0.925-$ 1.184), but concluded there could be a possible link between elevated CRP levels and colorectal cancer (Guo et al, 2013). Therefore, the link between markers of chronic inflammation and risk of colorectal cancer is still unclear.

We investigated the link between inflammation and colorectal cancer risk in a cohort of the Apolipoprotein Mortality Risk Study (AMORIS) Study ( $n=325599)$. In addition to commonly studied CRP, we also assessed albumin, haptoglobin and white blood cells as markers of inflammation in relation to risk of colorectal cancer. C-reactive protein, an acute phase reactant, is elevated in response to inflammation following a rise in proinflammatory interleukin-6 (IL-6) and is the most widely used marker to assess inflammation in clinic (Skinner et al, 2010). Similar to CRP, haptoglobin levels also rise in the presence of increased IL-6 levels (RodriguezHernandez et al, 2013). On the other hand, albumin levels drop in response to inflammation; hence, albumin is regarded as a negative acute phase reactant (Fox et al, 2013). Second, we studied prediagnostic levels of these inflammatory markers in relation to survival among colorectal cancer patients $(n=4764)$. We also considered metabolic disorders by assessing serum markers of glucose and lipid metabolism.

\section{MATERIALS AND METHODS}

Study population. The AMORIS Study has been described in further detail elsewhere (Holme et al, 2010). Briefly, this cohort consists of men and women from the greater Stockholm area in Sweden who underwent clinical laboratory testing at the Central Automation Laboratory (CALAB) in Stockholm, Sweden, with follow-up information collected from Swedish national registries. In CALAB, over 500 blood biomarkers were collected between 1986 and 1996. All the individuals at the time were either healthy individuals referred for clinical laboratory testing as part of a general health check-up or were outpatients. None of the individuals were in-patients at the time their blood samples were taken. Apart from the information on blood testing, no clinical data was included in the CALAB database. With a ten-digit personal identification number, the CALAB database was linked to several Swedish national registries such as the National Cancer Register, the Hospital Discharge Register, the Cause of Death Register, the consecutive Swedish Censuses during 1970-1990 and the National Register of Emigration. These databases provided data on socioeconomic status, vital status, cancer diagnosis, comorbidity and emigration. All aspects of the AMORIS Study complied with the Declaration of Helsinki and the ethics review board of Karolinska Institute approved the AMORIS Study.

For this study, all individuals aged 20 years and older with baseline measurements of CRP and albumin $(n=325599)$ were included, among which 218158 also had baseline haptoglobin levels measured, 96821 had leukocytes measurements and 57340 participants had body mass index (BMI) measurements. None of the participants had a history of cancer at baseline. Participants with measurements of serum inflammatory markers taken within 2 years before the end of follow-up were excluded to reduce the possibility of reverse causation.

Outcome assessment. The main outcome of interest was diagnosis of colorectal cancer as obtained from the Swedish Cancer Register using the International Code of Diseases, version 7 (ICD-7 code: 153-154). As a secondary outcome, we investigated mortality from colorectal cancer and from all causes for which we obtained information from the Cause of Death Register. The follow-up time for the primary outcome was defined as the time from baseline measurement entry until time of colorectal cancer diagnosis, death, emigration out of Sweden or the closing date of the study (31 December 2011), whichever came first. Those who were diagnosed with CRC in this study were then followed to assess death from all causes and from CRC as the second outcome. For the mortality outcomes, follow-up time was defined from the diagnosis of colorectal cancer to either death, end of follow-up or date of emigration out of Sweden, whichever came first.

Serum inflammatory markers. Serum CRP and haptoglobin levels were measured with an immunoturbidimetric assay (reagents from Orion Diagnostics, Espoo, Finland). These were analysed using fully automated multichannel analysers. For CRP, an Auto Chemist-PRISMA was used from 1985 to 1992 and from 1993 to 1996 a DAX96 from Technicon Instruments (Bayer Diagnostics, New York, NY, USA) was used. Hitachi-analysers (Mannheim, Germany) were used to analyse haptoglobin (Holme et al, 2010). At the time of laboratory examination (1985-1996), highsensitivity CRP (hs-CRP) was not available and CRP concentrations below the level of $10 \mathrm{mgl}^{-1}$ could not be discriminated. However, the cutoff point of $10 \mathrm{mgl}^{-1}$ is widely accepted as the upper limit of the health-associated reference range (Wilkins et al, 1998). Albumin was measured with a bromcresol green method. Leukocyte count was measured with routinely used haematology analysers from STKS Haematology System (Beckman Coulter Inc., Fullerton, CA, USA). Total imprecision calculated by the coefficient of variation was $12 \%$ for CRP, $5.6 \%$ for haptoglobin, $<1.8 \%$ for albumin and for $<2.7 \%$ for leukocytes (Wulaningsih et al, 2015). Central Automation Laboratory performed all laboratory procedure and complied with the WHO international federation of clinical chemistry protocols standard programmes (Jungner et al, 1998).

Covariates. In addition to the inflammatory markers of interest, information on serum levels of glucose, triglycerides (TGs) and total cholesterol (TC) levels were collected due to research indicating metabolic syndrome, specifically its components as potential confounders (Esposito et al, 2013). Glucose was measured with a glucose oxidase/peroxidase method (Holme et al, 2010). Total cholesterol and TGs were measured enzymatically with standardised procedures. Body mass index was calculated from weight $(\mathrm{kg})$ and height $(\mathrm{m})$ measured at CALAB. Information on education and social economic status (SES) was obtained from the national censuses. History of ulcerative colitis (UC) was obtained from the National Patient Register. Also from the National Patient Register, comorbidities were assessed as the Charlson comorbidity index (CCI), which consists of 17 groups of diseases with a specific weight assigned to each disease category (D'Hoore et al, 1996). These weights were then summed to obtain an overall score, resulting in four comorbidity levels $(0,1,2$ and $3+)$, indicating no comorbidity to severe comorbidity. Period of diagnosis was categorised (before and after 2008) to account for colorectal cancer screening introduced in Sweden from 2008 (Blom et al, 2014). Interval time was defined as time between blood test and the time of diagnosis of colorectal cancer. Information on tumour stage was available for 2474 out of 4764 colorectal cancer cases from the Swedish Cancer Registry.

Statistical analysis. First, risk of colorectal cancer associated with continuous log-transformed values of systemic inflammatory markers (C-reactive protein, albumin, haptoglobin and leukocytes) were analysed using unadjusted Cox proportional hazard regression models. For CRP, all logarithmic analysis was carried out with participants who had CRP values $>10 \mathrm{mgl}^{-1}$. Proportionality of the hazard was checked with Kaplan-Meier curves and the assumption of proportionality was not violated. Additionally, inflammatory markers were assessed as categories, with CRP divided into five categories $(<10,10-15,15-25,25-50$ and 
$>50 \mathrm{mgl}^{-1}$ ) and other markers assessed as quartiles. A linear test for trend was conducted by using categories as an ordinal scale. We subsequently conducted multivariable analyses with models adjusted for age (continuous), sex, educational level, SES, CCI and history of UC. Additional adjustments were carried out with continuous glucose, TG and TC levels to take into account the impact of obesity-related metabolic disorders on inflammation and CRC risk. In the subgroup with BMI, the same Cox regression analysis with similar adjustments was carried out to observe whether associations were similar between the participants who had BMI measurements and the total study population. We then conducted a similar analysis with an additional adjustment for BMI in this subgroup. Finally, stratification analyses were performed by dichotomised levels of glucose, TG and TC based on the NCEP guidelines (NCEP, 2001): 7, 1.71 and $6.50 \mathrm{mmoll}^{-1}$, respectively. Some participants may have had a transient rise in CRP due to acute infections; therefore, a sensitivity analysis was conducted by repeating analyses while excluding all participants with CRP $>20 \mathrm{mgl}^{-1}$

For the second outcome, the associations with continuous logarithmic and categories of systemic inflammatory markers (CRP, albumin, haptoglobin and leukocytes) were analysed using crude and multivariable Cox proportional hazard regression models. Two outcomes were analysed: all-cause death and colorectal cancer-specific death. The multivariable models were adjusted for age of diagnosis, interval time, period diagnosis and sex. A second model was carried out with additional adjustment for TNM staging.

All analyses were carried out using Statistical Analysis Systems (SAS) release 9.4 (SAS Institute, Cary, NC, USA).

\section{RESULTS}

During a mean follow-up time of 18 years, 4764 out of 325599 participants (1.46\%) developed invasive colorectal cancer. Table 1 shows participant characteristics by colorectal cancer diagnosis. Over $90 \%$ of participants were gainfully employed.

Higher levels of haptoglobin and leukocytes levels were associated with increased colorectal cancer risk in the crude model (Table 2). In the second model adjusted for age, sex, education, SES, CCI and UC, these trends weakened slightly, with HRs of 1.19 (95\% CI: 1.09-1.31) and 1.25 (95\% CI: 1.07-1.46) for highest vs lowest quartile in haptoglobin and leukocytes, respectively. When additionally adjusted for glucose, TG and TC levels, there was no large difference observed; for instance, the HR for the fourth quartile of haptoglobin was 1.17 (95\% CI: 1.06-1.28) and that of leukocytes was 1.21 (1.03-1.42), compared with the first quartiles of the markers. A strong inverse trend was observed between albumin and colorectal cancer risk in the crude model. However, upon adjustments (model 2) the trend became weaker $\left(P_{\text {trend }}=0.06\right)$. When additionally adjusted for metabolic markers, a borderline negative association was observed with an HR of 0.91 (95\% CI: 0.83-1.00) for the fourth compared with the first quartile $\left(P_{\text {trend }}=0.02\right)$. An additional test was carried out in the subgroup with information on BMI (Supplementary Table S2). In this model, similar underlying trends were observed. When adjusting the analysis for BMI in this subgroup, no marked changes were observed in the risk estimates and confidence intervals. Supplementary Table 3 shows associations between continuous $\log$ and categories of systemic inflammatory markers and colorectal cancer incidence, stratified by metabolic markers. No substantial interaction between levels of inflammatory markers and glucose, TG or TC was indicated $\left(P_{\text {interaction }}>0.05\right)$. A sensitivity analysis excluding those with CRP $>20$ to exclude acute inflammation showed similar findings (no results shown).
Table 1. Characteristics of study participants

\begin{tabular}{|c|c|c|c|}
\hline & $\begin{array}{c}\text { Colorectal } \\
\text { cancer, } \\
N=4764\end{array}$ & $\begin{array}{c}\text { No } \\
\text { colorectal, } \\
\text { cancer } \\
\mathbf{N}=320835\end{array}$ & $\begin{array}{c}\text { All } \\
\text { participants, } \\
N=325599\end{array}$ \\
\hline $\begin{array}{l}\text { Age (years) } \\
\text { Mean (s.d.) }\end{array}$ & $56.21(11.00)$ & 45.66 (13.92) & 45.81 (13.94) \\
\hline $\begin{array}{l}\text { SES } \\
\text { White collar } \\
\text { Blue collar } \\
\text { Not gainfully } \\
\text { employed or missing }\end{array}$ & $\begin{array}{c}2465(51.74) \\
1908(40.05) \\
391(8.21)\end{array}$ & $\begin{array}{c}151315(47.16) \\
137574(42.88) \\
31946(9.96)\end{array}$ & $\begin{array}{c}153780(47.23) \\
139482(42.84) \\
32337(9.93)\end{array}$ \\
\hline $\begin{array}{l}\text { Education category } \\
\text { Low } \\
\text { Middle } \\
\text { High } \\
\text { Missing }\end{array}$ & $\begin{array}{c}1579(33.14) \\
1880(39.46) \\
1155(24.24) \\
150(3.15)\end{array}$ & $\begin{array}{c}78522(24.47) \\
139964(43.62) \\
92187(28.73) \\
10162(3.17)\end{array}$ & $\begin{array}{c}80101(24.60) \\
141844(43.56) \\
93342(28.67) \\
10312(3.17)\end{array}$ \\
\hline $\begin{array}{l}\text { Follow-up time (years) } \\
\text { Mean (s.d.) } \\
\text { Median } \\
\text { Min } \\
\text { Max }\end{array}$ & $\begin{array}{c}12.88(5.50) \\
13.00 \\
2.01 \\
24.58\end{array}$ & $\begin{array}{c}18.64(4.51) \\
19.04 \\
2.00 \\
24.83\end{array}$ & $\begin{array}{c}18.56(4.58) \\
18.97 \\
2.00 \\
22.19\end{array}$ \\
\hline $\begin{array}{l}\text { Comorbidity index } \\
0 \\
1 \\
2 \\
3+\end{array}$ & $\begin{array}{c}4385(92.04) \\
282(5.92) \\
63(1.32) \\
34(0.71)\end{array}$ & $\begin{array}{c}301930(94.11) \\
13567(4.23) \\
3226(1.01) \\
2112(0.66)\end{array}$ & $\begin{array}{c}306315(94.08) \\
13849(4.25) \\
3289(1.01) \\
2146(0.66)\end{array}$ \\
\hline Ulcerative colitis & $7(0.15)$ & $292(0.09)$ & $299(0.09)$ \\
\hline $\begin{array}{l}\mathrm{CRP}\left(\mathrm{mgl}^{-1}\right) \\
\text { Mean (s.d.) }\end{array}$ & $18.92(39.60)$ & $19.43(38.35)$ & $19.42(38.37)$ \\
\hline $\begin{array}{l}\text { Albumin }\left(\left.g\right|^{-1}\right) \\
\text { Mean (s.d.) }\end{array}$ & $42.48(2.69)$ & $43.30(2.87)$ & $43.29(2.87)$ \\
\hline $\begin{array}{l}\text { Haptoglobin }\left(\mathrm{gl}^{-1}\right) \\
\text { Mean (s.d.) }\end{array}$ & $1.10(0.31)$ & $1.04(0.3)$ & $1.05(0.30)$ \\
\hline $\begin{array}{l}\text { Leukocytes }\left(10^{9} / \mathrm{l}\right) \\
\text { Mean (s.d.) }\end{array}$ & $6.68(1.95)$ & $6.61(2.15)$ & $6.61(2.15)$ \\
\hline
\end{tabular}

Table 3 shows the characteristics of participants who were diagnosed with colorectal cancer by survival status. Out of the 4764 persons diagnosed with CRC, 2257 died during follow-up, of which 1467 died specifically of CRC. The mean follow-up time from diagnosis to death was 4.64 years.

Table 4 displays associations between prediagnostic inflammatory markers and all-cause death. Upon adjustment for age of diagnosis, sex, interval time and period of diagnosis, positive associations were observed for haptoglobin (HR: 1.16; 95\% CI: 1.02-1.32 for the fourth quartile compared with the first) and leukocytes (HR: 1.53; 95\% CI: $1.23-1.90$ for the fourth quartile compared with the first) in relation to risk of dying from all causes. No associations were observed for albumin in the multivariable models. Additional adjustments for TNM staging showed similar trends (Table 4).

When assessing colorectal cancer-specific death in the crude models, significant trends for albumin, haptoglobin and leukocytes were observed (Table 5). In the fully adjusted models, there was only a significant association between haptoglobin and colorectal cancer death (HR: 1.19; 95\% CI: 1.01-1.41) for the highest compared with the lowest quartile.

\section{DISCUSSION}

This is the largest study to date assessing the association between colorectal cancer risk and widely available clinical markers of inflammation in addition to CRP. To our knowledge, this is the first study to assess the relationship between haptoglobin, albumin and leukocytes in relation to CRC incidence and survival. Despite the lack of an association with CRP, we found an increased risk of 
Table 2. Associations between inflammatory markers and risk of CRC

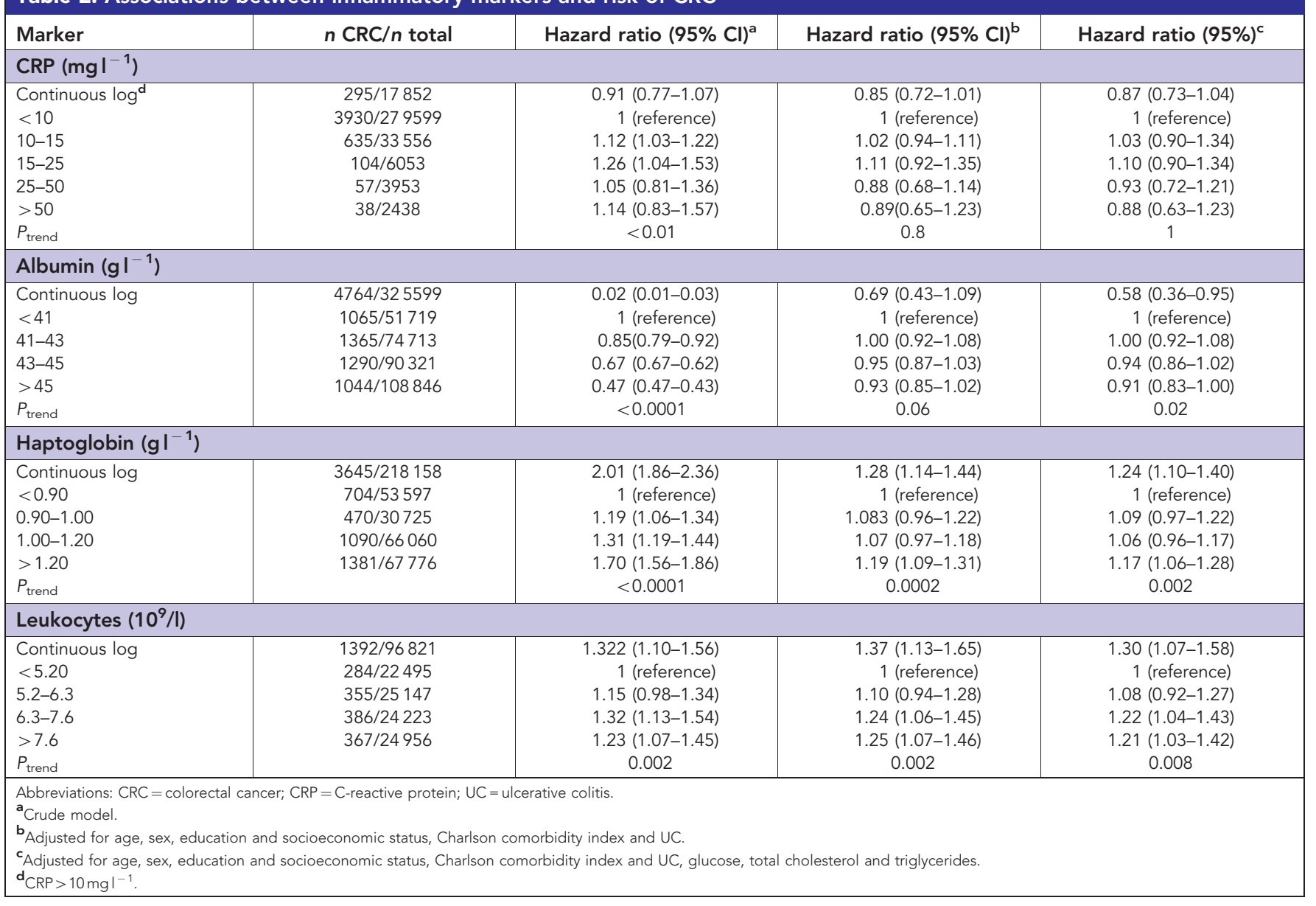

colorectal cancer with higher levels of haptoglobin and leukocytes and a borderline inverse association with albumin. For colorectal cancer-specific death, the only positive association observed was with haptoglobin.

Biological studies linking inflammation to colorectal cancer and cancer development in general have suggested a role of cancer initiation and promotion by reactive oxygen species, which is produced during inflammation (Wiseman and Halliwell, 1996; Waris and Ahsan, 2006). Proinflammatory cytokine IL-6 released during inflammation may trigger the activation of signal transducer and activator of transcription 3 (STAT3) and nuclear factor- $\kappa \mathrm{B}$ (NF- $\kappa \mathrm{B}$ ) pathways (Hodge et al, 2005; Wang et al, 2009; $\mathrm{Yu}$ et al, 2009). Activation of these pathways has been widely implicated in colitis-associated colorectal cancer (Wang et al, 2009). Additionally, increased levels of circulating proinflammatory cytokines are also observed in chronic systemic inflammation (Gabay, 2006). These signalling pathways may induce upregulation of genes involved in cell proliferation and survival, and increased localisation of $\beta$-catenin, which contributes to colorectal cancer carcinogenesis (Bollrath et al, 2009). In the context of cancer progression, current experimental research suggests that the activation of STAT3 from cytokine IL-6 suppresses the MIR34A gene (Rose-John, 2012; Rokavec et al, 2014), resulting in the activation of epithelial-to-mesenchymal transition and subsequent metastasis of the cancer (Hahn et al, 2013; Siemens et al, 2013; Rokavec et al, 2014).

This study showed significant positive associations between prediagnostic markers haptoglobin and leukocytes with colorectal cancer risk. In recent years, there has been increasing evidence linking serum haptoglobin and other cancers; for instance, breast cancer (Wulaningsih et al, 2015). Experimental studies have shown that haptoglobin contributes to increased oxidative stress and low-grade chronic inflammation (Ye et al, 2003; ÁlvarezBlasco et al, 2009). Serum haptoglobin levels rise for longer periods following an external insult compared with other inflammatory markers such as CRP, which fluctuates and drops rapidly after a proinflammatory stimulus (Gabay and Kushner, 1999). This variation in bioavailability of the markers may explain the difference in results observed between the two markers. Furthermore, this may indicate that haptoglobin, in addition to its role as an inflammatory marker, could be directly involved in CRC carcinogenesis. Further studies are necessary to contrast the role of haptoglobin with other markers such as CRP as markers of chronic inflammation in the context of cancer. Higher quartiles of leukocytes showed a positive association with risk of colorectal cancer. This positive association agrees with findings indicating the role of IL-6, which is released by specific leukocytes, in CRC carcinogenesis (Patel et al, 2014).

In keeping with the majority of current studies, our finding found no evidence of association between elevated CRP and CRC. As already mentioned, of the 19 prospective studies that have been published to date, only nine found that CRP is associated with an increased risk of colorectal cancer (Supplementary Table S1). However, the largest number of colorectal cancer cases among these prior studies was 729 (Lee et al, 2011). In addition to sample size, adjustments for potential confounders such as BMI and other lifestyle factors may explain the differences in estimates. Although our analysis in the subgroup with BMI information was hampered by low statistical power, we observed similar results before and after adjustment for BMI or markers of glucose and lipid metabolisms. 
Table 3. Characteristics of survival study participants

\begin{tabular}{|c|c|c|c|c|}
\hline & All-cause death $(n=2257)$ & CRC death $(n=1467)$ & Alive $(n=2507)$ & All CRC patients $(n=4764)$ \\
\hline Age at diagnosis & $71.16(10.72)$ & $69.32(10.78)$ & $67.04(10.06)$ & $68.99(10.58)$ \\
\hline $\begin{array}{l}\text { Sex } \\
\text { Male } \\
\text { Female }\end{array}$ & $\begin{array}{l}1329(48.47) \\
928(45.90)\end{array}$ & $\begin{array}{l}838(30.56) \\
629(13.20)\end{array}$ & $\begin{array}{l}1413(51.53) \\
1094(54.10)\end{array}$ & $\begin{array}{l}2742(57.66) \\
2022(42.44)\end{array}$ \\
\hline $\begin{array}{l}\text { Interval between marker } \\
\text { measurements and diagnosis } \\
\text { (years) }\end{array}$ & $10.91(5.17)$ & $11.21(5.23)$ & $14.46(5.2)$ & $12.78(5.50)$ \\
\hline Follow-up since diagnosis (years) & $2.98(3.35)$ & $2.00(2.12)$ & $6.13(4.87)$ & $4.64(4.50)$ \\
\hline $\begin{array}{l}\text { Period diagnosis } \\
\quad<2008 \\
>2008\end{array}$ & $\begin{array}{c}1959(86.80) \\
298(13.20)\end{array}$ & $\begin{array}{c}1246(84.94) \\
221(15.06)\end{array}$ & $\begin{array}{l}1432(57.12) \\
1075(42.88)\end{array}$ & $\begin{array}{l}3391(77.18) \\
1373(28.82)\end{array}$ \\
\hline $\begin{array}{l}\text { TNM staging } \\
\text { Tumour } \\
\leqslant \mathrm{T} 2 \\
>\mathrm{T} 2 \\
\text { Tx/unknown } \\
\text { Nodes } \\
\text { No } \\
\text { Yes } \\
\text { Nx/Missing } \\
\text { Metastasis } \\
\text { No } \\
\text { Yes } \\
\text { Mx/Unknown }\end{array}$ & $\begin{array}{c}118(5.23) \\
656(29.07) \\
1483(65.71) \\
\\
292(12.94) \\
443(19.63) \\
1522(67.43) \\
\\
449(19.89) \\
429(19.01) \\
1379(61.10)\end{array}$ & $\begin{array}{c}54(3.68) \\
470(32.04) \\
943(64.28) \\
\\
138(9.41) \\
362(24.68) \\
967(65.92) \\
\\
237(16.16) \\
391(26.65) \\
839(57.19)\end{array}$ & $\begin{array}{c}588(23.45) \\
1112(44.36) \\
807(32.19) \\
\\
1051(41.92) \\
577(23.02) \\
879(35.06) \\
\\
1204(48.03) \\
110(4.39) \\
1193(47.59)\end{array}$ & $\begin{array}{c}706(14.82) \\
1768(37.11) \\
2290(48.07) \\
1343(28.19) \\
1020(21.41) \\
2401(50.40) \\
1653(34.70) \\
539(11.31) \\
2572(53.99)\end{array}$ \\
\hline $\begin{array}{l}\text { Markers } \\
\text { CRP (mg }\left.\right|^{-1} \text { ) } \\
\text { Mean (s.d.) } \\
\text { Albumin }\left(\left.g\right|^{-1} \text { ) }\right. \\
\text { Mean (s.d.) } \\
\text { Haptoglobin }\left(\left.g\right|^{-1} \text { ) }\right. \\
\text { Mean (s.d.) } \\
\text { Leukocytes (10 } \\
\text { Mean (s.d.) }\end{array}$ & $\begin{array}{l}18.92(39.60) \\
42.14(2.72) \\
1.13(0.33) \\
6.76(1.97)\end{array}$ & $\begin{array}{l}18.35(31.35) \\
42.27(2.71) \\
1.12(0.32) \\
6.74(2.06)\end{array}$ & $\begin{array}{c}19.43(38.35) \\
42.78(2.63) \\
1.07(0.29) \\
6.59(1.93)\end{array}$ & $\begin{array}{l}18.92(39.60) \\
42.48(2.96) \\
1.10(0.31) \\
6.68(1.95)\end{array}$ \\
\hline
\end{tabular}

\section{Table 4. Associations between prediagnostic inflammatory markers and all-cause death}

\begin{tabular}{|c|c|c|c|c|}
\hline Marker & $N$ event/ $N$ total & Hazard ratios $(95 \% \mathrm{Cl})^{a}$ & Hazard ratios $(95 \% \mathrm{Cl})^{b}$ & Hazard ratios $(95 \% \mathrm{Cl})^{\mathrm{c}}$ \\
\hline \multicolumn{5}{|l|}{$\mathrm{CRP}\left(\mathrm{mg} \mathrm{I}^{-1}\right)$} \\
\hline $\begin{array}{l}\text { Continuous } \log ^{\mathrm{d}} \\
<10 \\
10-15 \\
15-25 \\
25-50 \\
>50 \\
P_{\text {trend }}\end{array}$ & $\begin{array}{c}149 / 295 \\
1834 / 3930 \\
322 / 635 \\
51 / 104 \\
29 / 57 \\
21 / 38\end{array}$ & $\begin{array}{c}0.96 \text { (0.79-1.18) } \\
1 \text { (reference) } \\
1.06(0.94-1.19) \\
1.01(0.77-1.34) \\
1.17(0.81-1.69) \\
1.11(0.72-1.70) \\
0.26\end{array}$ & $\begin{array}{c}0.93 \text { (0.75-1.15) } \\
1 \text { (reference) } \\
1.04(0.92-1.17) \\
0.86(0.65-1.14) \\
1.17(0.81-1.69) \\
1.03(0.67-1.58) \\
0.8\end{array}$ & $\begin{array}{c}0.92 \text { (0.74-1.14) } \\
1 \text { (reference) } \\
1.02(0.91-1.15) \\
0.92(0.70-1.22) \\
1.28(0.89-1.85) \\
1.07(0.70-1.65) \\
0.5\end{array}$ \\
\hline \multicolumn{5}{|l|}{ Albumin } \\
\hline $\begin{array}{l}\text { Continuous log } \\
<41 \\
41-43 \\
43-45 \\
>45 \\
P_{\text {trend }}\end{array}$ & $\begin{array}{l}2256 / 4764 \\
615 / 1065 \\
626 / 1365 \\
601 / 1290 \\
415 / 1044\end{array}$ & $\begin{array}{c}0.13(0.07-0.24) \\
1 \text { (reference) } \\
0.76(0.68-0.85) \\
0.79(0.71-0.89) \\
0.68(0.60-0.77) \\
\quad<0.0001\end{array}$ & $\begin{array}{c}0.63(0.32-1.25) \\
1 \text { (reference) } \\
0.82(0.74-0.92) \\
0.97(0.86-1.08) \\
0.90(0.79-1.02) \\
0.44\end{array}$ & $\begin{array}{c}0.57(0.29-1.14) \\
1 \text { (reference) } \\
0.88(0.78-0.98) \\
1.00(0.89-1.12) \\
0.88(0.77-1.00) \\
0.28\end{array}$ \\
\hline \multicolumn{5}{|l|}{ Haptoglobin } \\
\hline $\begin{array}{l}\text { Continuous log } \\
<0.90 \\
0.90-1.00 \\
1.00-1.20 \\
>1.20 \\
P_{\text {trend }} \\
\end{array}$ & $\begin{array}{l}1793 / 3645 \\
324 / 704 \\
192 / 470 \\
523 / 1090 \\
755 / 1381\end{array}$ & $\begin{array}{c}1.38(1.16-1.63) \\
1 \text { (reference) } \\
0.87(0.73-1.04) \\
1.04(0.90-1.19) \\
1.22(1.07-1.39) \\
0.0001\end{array}$ & $\begin{array}{l}1.27(1.07-1.50) \\
1 \text { (reference) } \\
0.87(0.72-1.03) \\
1.02(0.89-1.17) \\
1.16(1.02-1.32) \\
0.002\end{array}$ & $\begin{aligned} & 1.28(1.08-1.51) \\
& 1 \text { (reference) } \\
& 0.91(0.76-1.08) \\
& 1.04(0.91-1.20) \\
& 1.19(1.05-1.36) \\
& 0.001\end{aligned}$ \\
\hline \multicolumn{5}{|c|}{ Leukocytes $\left(10^{9} / \mathrm{I}\right)$} \\
\hline $\begin{array}{l}\text { Continuous log } \\
<5.20 \\
5.2-6.3 \\
6.3-7.6 \\
>7.6 \\
P_{\text {trend }} \\
\end{array}$ & $\begin{array}{l}741 / 1392 \\
136 / 284 \\
194 / 355 \\
201 / 386 \\
210 / 367\end{array}$ & $\begin{array}{c}1.42 \text { (1.10-1.85) } \\
1 \text { (reference) } \\
1.30(1.04-1.62) \\
1.23(0.99-1.53) \\
1.41(1.14-1.75) \\
0.006 \\
\end{array}$ & $\begin{aligned} & 1.64(1.25-2.15) \\
& 1 \text { (reference) } \\
& 1.30(1.04-1.62) \\
& 1.19(0.95-1.48) \\
& 1.53(1.23-1.90) \\
&<0.001 \\
&\end{aligned}$ & $\begin{array}{c}1.63(1.26-2.12) \\
1 \text { (reference) } \\
1.35(1.08-1.69) \\
1.29(1.04-1.61) \\
1.55(1.25-1.93) \\
<0.001 \\
\end{array}$ \\
\hline \multicolumn{5}{|c|}{$\begin{array}{l}\text { Abbreviations: } \mathrm{Cl}=\text { confidence interval; } \mathrm{CRP}=\mathrm{C} \text {-reactive protein; } \mathrm{TNM}=\text { tumour node metastasis. } \\
{ }^{\text {a }} \text { Crude model. } \\
{ }^{\mathrm{b}} \text { Adjusted for age of diagnosis, interval time, period of diagnosis and sex. } \\
{ }^{c} \text { Adjusted for age of diagnosis, interval time, period of diagnosis and sex and TNM staging. } \\
{ }^{d} C R P>10 \mathrm{mgl}^{-1} \text {. }\end{array}$} \\
\hline
\end{tabular}


overtime. Since cancer may influence levels of serum inflammatory markers, residual confounding may still have occurred despite exclusion of participants with history of any cancer at baseline. Owing to the rounding of the marker levels to 2 decimal places, the distribution of the markers was not completely equal between the quartiles. In this study, we were not able to adjust for exercise, alcohol intake, fruit and vegetable and/or fibre intake, aspirin and other NSAID use owing to the lack of information in this study. We did not have information on Crohn's disease; however, the history of UC was included in our analysis to account for inflammatory bowel disease. The AMORIS population is representative of the general working population of Stockholm (Walldius et al, 2001). However, this healthy cohort effect does not influence the internal validity of the study. The markers assessed in this study were measured at one single point in time, which may be prone to a non-differential measurement error and this may have resulted in the underestimation of the associations observed in this study. Finally, detailed histopathological information of the tumour was not available and it may benefit future studies to further explore whether prediagnostic inflammation corresponds to any specific or molecular subtypes of colorectal cancer.

\section{CONCLUSION}

We found that altered levels of prediagnostic inflammatory markers may be associated with an increased risk of colorectal cancer and worse cancer-specific survival after diagnosis. These findings support the importance of systemic inflammation preceding cancer diagnosis in affecting subsequent risk of incidence and survival. Therefore, this denotes the importance to study the roots of systemic inflammation and pathways specific to the development and progression of colorectal cancer.

\section{ACKNOWLEDGEMENTS}

The research was funded/supported by the National Institute for Health Research (NIHR) Biomedical Research Centre based at the Guy's and St Thomas' NHS Foundation Trust and King's College London. The views expressed are those of the author(s) and not necessarily those of the CRUK, NHS, the NIHR or the Department of Health.

\section{CONFLICT OF INTEREST}

$\mathrm{NH}$ is employed by AstraZeneca. However, the views expressed in this study are his own and not those of AstraZeneca's. The other authors declare no conflict of interest.

\section{REFERENCES}

NCEP (2001) Executive Summary of The Third Report of The National Cholesterol Education Program (NCEP) Expert Panel on Detection, Evaluation, and Treatment of High Blood Cholesterol In Adults (Adult Treatment Panel III). JAMA 285(19): 2486-2497.

Aleksandrova K, Jenab M, Boeing H, Jansen E, Bueno-de-Mesquita HB, Rinaldi S, Riboli E, Overvad K, Dahm CC, Olsen A, Tjonneland A, Boutron-Ruault MC, Clavel-Chapelon F, Morois S, Palli D, Krogh V, Tumino R, Vineis P, Panico S, Kaaks R, Rohrmann S, Trichopoulou A, Lagiou P, Trichopoulos D, van Duijnhoven FJ, Leufkens AM, Peeters PH, Rodriguez L, Bonet C, Sanchez MJ, Dorronsoro M, Navarro C, Barricarte A, Palmqvist R, Hallmans G, Khaw KT, Wareham N, Allen NE, Spencer E, Romaguera D, Norat T, Pischon T (2010) Circulating C-reactive protein concentrations and risks of colon and rectal cancer: a nested case-control study within the European Prospective Investigation into Cancer and Nutrition. Am J Epidemiol 172(4): 407-418.
Allin KH, Bojesen SE, Nordestgaard BG (2009) Baseline C-reactive protein is associated with incident cancer and survival in patients with cancer. J Clin Oncol 27(13): 2217-2224.

Álvarez-Blasco F, Martínez-García M, Luque-Ramírez M, Parraza N, San Millán JL, Escobar-Morreale HF (2009) Role of haptoglobin in polycystic ovary syndrome (PCOS), obesity and disorders of glucose tolerance in premenopausal women. PLoS One 4: e5606.

Blom J, Kilpelainen S, Hultcrantz R, Tornberg S (2014) Five-year experience of organized colorectal cancer screening in a Swedish population-increased compliance with age, female gender, and subsequent screening round. $J$ Med Screen 21(3): 144-150.

Bollrath J, Phesse TJ, von Burstin VA, Putoczki T, Bennecke M, Bateman T, Nebelsiek T, Lundgren-May T, Canli O, Schwitalla S, Matthews V, Schmid RM, Kirchner T, Arkan MC, Ernst M, Greten FR (2009) Gp130-mediated Stat3 activation in enterocytes regulates cell survival and cell-cycle progression during colitis-associated tumorigenesis. Cancer Cell 15(2): 91-102.

D'Hoore W, Bouckaert A, Tilquin C (1996) Practical considerations on the use of the Charlson comorbidity index with administrative data bases. J Clin Epidemiol 49(12): 1429-1433.

Esposito K, Chiodini P, Capuano A, Bellastella G, Maiorino MI, Rafaniello C, Panagiotakos DB, Giugliano D (2013) Colorectal cancer association with metabolic syndrome and its components: a systematic review with metaanalysis. Endocrine 44(3): 634-647.

Fox P, Hudson M, Brown C, Lord S, Gebski V, De Souza P, Lee CK (2013) Markers of systemic inflammation predict survival in patients with advanced renal cell cancer. Br J Cancer 109(1): 147-153.

Gabay C (2006) Interleukin-6 and chronic inflammation. Arthritis Res Ther 8(Suppl 2): S3.

Gabay C, Kushner I (1999) Acute-phase proteins and other systemic responses to inflammation. N Engl J Med 340(6): 448-454.

Guo YZ, Pan L, Du CJ, Ren DQ, Xie XM (2013) Association between C-reactive protein and risk of cancer: a meta-analysis of prospective cohort studies. Asian Pac J Cancer Prev 14(1): 243-248.

Hahn S, Jackstadt R, Siemens H, Hunten S, Hermeking H (2013) SNAIL and miR-34a feed-forward regulation of ZNF281/ZBP99 promotes epithelialmesenchymal transition. Embo J 32(23): 3079-3095.

Hanahan D, Weinberg RA (2011) Hallmarks of cancer: the next generation. Cell 144(5): 646-674.

Hodge DR, Hurt EM, Farrar WL (2005) The role of IL-6 and STAT3 in inflammation and cancer. Eur J Cancer 41(16): 2502-2512.

Holme I, Aastveit AH, Hammar N, Jungner I, Walldius G (2010) Inflammatory markers, lipoprotein components and risk of major cardiovascular events in 65005 men and women in the Apolipoprotein MOrtality RISk study (AMORIS). Atherosclerosis 213(1): 299-305.

Jess T, Rungoe C, Peyrin-Biroulet L (2012) Risk of colorectal cancer in patients with ulcerative colitis: a meta-analysis of population-based cohort studies. Clin Gastroenterol Hepatol 10(6): 639-645.

Jungner I, Marcovina SM, Walldius G, Holme I, Kolar W, Steiner E (1998) Apolipoprotein B and A-I values in 147576 Swedish males and females, standardized according to the World Health Organization-International Federation of Clinical Chemistry First International Reference Materials. Clin Chem 44(8 Part 1): 1641-1649.

Lee S, Choe JW, Kim HK, Sung J (2011) High-sensitivity C-reactive protein and cancer. J Epidemiol 21(3): 161-168.

Meira LB, Bugni JM, Green SL, Lee CW, Pang B, Borenshtein D, Rickman BH, Rogers AB, Moroski-Erkul CA, McFaline JL, Schauer DB, Dedon PC, Fox JG, Samson LD (2008) DNA damage induced by chronic inflammation contributes to colon carcinogenesis in mice. J Clin Invest 118: 2516-2525.

Patel SA, Bhambra U, Charalambous MP, David RM, Edwards RJ, Lightfoot T, Boobis AR, Gooderham NJ (2014) Interleukin-6 mediated upregulation of CYP1B1 and CYP2E1 in colorectal cancer involves DNA methylation, miR27b and STAT3. Br J Cancer 111(12): 2287-2296.

Reuter S, Gupta SC, Chaturvedi MM, Aggarwal BB (2010) Oxidative stress, inflammation, and cancer: How are they linked? Free Radic Biol Med 49(11): 1603-1616.

Rodriguez-Hernandez H, Simental-Mendia LE, Rodriguez-Ramirez G, Reyes-Romero MA (2013) Obesity and inflammation: epidemiology, risk factors, and markers of inflammation. Int J Endocrinol 2013: 678159.

Rokavec M, Oner MG, Li H, Jackstadt R, Jiang L, Lodygin D, Kaller M, Horst D, Ziegler PK, Schwitalla S, Slotta-Huspenina J, Bader FG, Greten FR, Hermeking H (2014) IL-6R/STAT3/miR-34a feedback loop promotes 
EMT-mediated colorectal cancer invasion and metastasis. J Clin Invest 124(4): 1853-1867.

Rose-John S (2012) IL-6 trans-signaling via the soluble IL-6 receptor: importance for the pro-inflammatory activities of IL-6. Int J Biol Sci 8(9): 1237-1247.

Satagopan JM, Ben-Porat L, Berwick M, Robson M, Kutler D, Auerbach AD (2004) A note on competing risks in survival data analysis. Br J Cancer 91(7): 1229-1235.

Siemens H, Neumann J, Jackstadt R, Mansmann U, Horst D, Kirchner T, Hermeking H (2013) Detection of miR-34a promoter methylation in combination with elevated expression of c-Met and beta-catenin predicts distant metastasis of colon cancer. Clin Cancer Res 19(3): $710-720$.

Skinner AC, Steiner MJ, Henderson FW, Perrin EM (2010) Multiple markers of inflammation and weight status: cross-sectional analyses throughout childhood. Pediatrics 125(4): e801-e809.

Van Hemelrijck M, Jungner I, Walldius G, Garmo H, Binda E, Hayday A, Lambe M, Holmberg L, Hammar N (2011) Risk of prostate cancer is not associated with levels of C-reactive protein and other commonly used markers of inflammation. Int J Cancer 129(6): 1485-1492.

Walldius G, Jungner I, Holme I, Aastveit AH, Kolar W, Steiner E (2001) High apolipoprotein B, low apolipoprotein A-I, and improvement in the prediction of fatal myocardial infarction (AMORIS study): a prospective study. Lancet 358(9298): 2026-2033.

Wang S, Liu Z, Wang L, Zhang X (2009) NF-kappaB signaling pathway, inflammation and colorectal cancer. Cell Mol Immunol 6(5): 327-334.
Waris G, Ahsan H (2006) Reactive oxygen species: role in the development of cancer and various chronic conditions. J Carcinog 5(1): 14.

Wilkins J, Gallimore JR, Moore EG, Pepys MB (1998) Rapid automated high sensitivity enzyme immunoassay of C-reactive protein. Clin Chem 44(6 Part 1): 1358-1361.

Wiseman H, Halliwell B (1996) Damage to DNA by reactive oxygen and nitrogen species: role in inflammatory disease and progression to cancer. Biochem J 313(Part 1): 17-29.

Wulaningsih W, Holmberg L, Garmo H, Malmstrom H, Lambe M, Hammar N, Walldius G, Jungner I, Van Hemelrijck M (2015) Prediagnostic serum inflammatory markers in relation to breast cancer risk, severity at diagnosis and survival in breast cancer patients. Carcinogenesis 36(10): 1121-1128.

Ye B, Cramer DW, Skates SJ, Gygi SP, Pratomo V, Fu L, Horick NK, Licklider LJ, Schorge JO, Berkowitz RS, Mok SC (2003) Haptoglobin-alpha subunit as potential serum biomarker in ovarian cancer: identification and characterization using proteomic profiling and mass spectrometry. Clin Cancer Res 9(8): 2904-2911.

Yu H, Pardoll D, Jove R (2009) STATs in cancer inflammation and immunity: a leading role for STAT3. Nat Rev Cancer 9(11): 798-809.

This work is published under the standard license to publish agreement. After 12 months the work will become freely available and the license terms will switch to a Creative Commons AttributionNonCommercial-Share Alike 4.0 Unported License.

Supplementary Information accompanies this paper on British Journal of Cancer website (http://www.nature.com/bjc) 